\title{
Consciência da "Estrutura Argumentativa" e Produção Textual ${ }^{1}$
}

\author{
Regina Pinheiro \\ Universidade de Campinas \\ Selma Leitão ${ }^{2}$ \\ Universidade Federal de Pernambuco
}

\begin{abstract}
RESUMO - A suposição cognitivista de que a consciência de um "esquema argumentativo" oriente as produções textuais dos indivíduos está longe de ser pacífica. Alternativamente, sugere-se que os elementos incluídos num texto seriam determinados pela consciência a respeito de parâmetros da situação de produção textual (finalidade, destinatário, etc.). Partindo-se desta controvérsia, investigou-se em que medida a reflexão sobre a "estrutura argumentativa" exerceria um impacto sobre os elementos que crianças e adultos jovens incorporariam a seus textos. A análise dos resultados mostrou que: ponto de vista e justificativa foram os elementos considerados indispensáveis a uma escrita argumentativa. Antecipação de contra-argumentos foi vista como relevante para a consecução do objetivo persuasivo do texto apenas quando eram rebatidos. A reflexão sobre elementos da "estrutura argumentativa" nem sempre correspondeu à inclusão destes nos textos produzidos. Tal inclusão dependeu primordialmente da avaliação dos elementos que mais contribuiriam para a consecução da finalidade persuasiva do texto - consciência retórica.
\end{abstract}

Palavras-chave: argumentação; consciência metatextual; escrita argumentativa.

\section{Awareness of the "Argumentative Structure" and Textual Production}

\begin{abstract}
The cognitive supposition that the awareness of an "argumentative scheme" gives orientation to the textual productions of individuals is rather controversial. As an alternative, it is suggested that the elements included in a text are determined by the awareness regarding the parameters of the situation of textual production (finality, the receiver, etc.). Starting from this controversy, the study investigated to which extent the reflection over the "argumentative structure" would exercise an impact over the elements that children and young adults would incorporate into their texts. The analysis of the results showed that: point of view and justification were the elements considered indispensable to an argumentative writing. The anticipation of counter-arguments was seen as relevant for the success of the persuasive objective of the text only when they were refuted. The reflection over elements of the "argumentative structure" did not always correspond to their inclusion in the texts produced. Such inclusion depended primarily on the evaluation of the elements that most contributed to the success of the persuasive finality of the text - rhetorical awareness.
\end{abstract}

Key words: argumentation; metatextual awareness; argumentative writing.

O presente estudo se insere nas linhas de investigação que exploraram a relação entre a consciência/conhecimento que indivíduos demonstram possuir sobre a chamada "estrutura prototípica" de textos argumentativos e a presença dessa mesma estrutura em textos escritos que produzem. Estruturas prototípicas são aqui entendidas como modelos abstratos de tipos textuais (narração, argumentação, etc.) que se diferenciam entre si pela natureza dos elementos lingüísticos que os constituem e certos modos de articulação que lhes são característicos.

A suposição de que a consciência/conhecimento de "estruturas prototípicas" seja relevante no processo de produção

1 O estudo aqui reportado fez parte da dissertação de mestrado da primeira autora realizada sob orientação da segunda. As autoras agradecem ao CNPq pelo apoio concedido à realização desse trabalho na forma de bolsa de mestrado e de produtividade em pesquisa, respectivamente.

2 Endereço: Pós-Graduação em Psicologia Cognitiva, $\mathrm{CFCH}, 8^{\circ}$. Andar, Cidade Universitária, Recife, PE, Brasil 50670-901. E-mail: selma_leitao2001@yahoo.com de textos escritos está longe de ser pacífica (Brassart, 1996; Fayol citado em Rego, 2005; Stein, 1988). Num dos pólos da controvérsia, situam-se posições cognitivistas que conferem às estruturas textuais o estatuto de representações cognitivas abstratas (Adam, 1992, Van Dijk, 1992) que precederiam os textos efetivamente produzidos e desempenhariam em relação a estes o papel de modelos. Por outro lado, autores que divergem dessa perspectiva preferem tratar as chamadas estruturas ou protótipos textuais, não como modelos cognitivos e, sim, como "construtos teóricos, elaborados secundariamente a partir do exame das seqüências empiricamente observáveis nos textos" (Bronckart, 1999, p. 233). Caso caiba a tais estruturas algum papel de modelo que orienta o escritor em seu processo de produção textual, isso se daria "apenas como generalização das diversas práticas planificadoras observáveis no intertexto" (Bronckart, 1999, p. 233, negrito no original). A seleção dos elementos que entram na composição de um texto poderia ser determinada simplesmente pela consciência do escritor a respeito de parâmetros da situação em que o texto é produzido (aspectos pragmáticos) tais como: finalidade comunicativa, tipo de destinatário, etc. (Coirier, Andriessen \& Chanquoy, 1999; Coirier, Pouit \& Golder, 2000; Leitão, 2003). 
Partindo da controvérsia acima delineada, investigou-se, no presente estudo, em que medida a consciência que os indivíduos teriam dos elementos constituintes da "estrutura prototípica" da argumentação se relacionaria à tendência dos mesmos indivíduos incorporarem tais elementos nos textos que produzissem. Esta relação foi aqui investigada procurando-se responder especificamente às seguintes questões: Em que medida os diferentes elementos que constituem a "estrutura argumentativa" são considerados, pelo escritor, relevantes para o alcance da finalidade última da argumentação, qual seja, o convencimento do destinatário? (note-se que, embora os termos convencer e persuadir não sejam usados como sinônimos na retórica (Perelman \& OlbrechtTyteca, 1958/1996), não se confere a tais termos nenhuma diferença relevante no presente trabalho). Há uma relação entre os elementos que os indivíduos julgam ser importantes para a consecução do objetivo comunicativo do texto e os elementos que, de fato, incorporam nos textos que produzem? O que indivíduos de diferentes faixas etárias consideram ser um "bom" texto argumentativo (de que elementos é constituído), uma vez considerada a finalidade para a qual o texto é produzido? Antes, porém, de especificar detalhes do estudo conduzido, algumas concepções-chave que constituíram o quadro de referência desse estudo são apresentadas.

\section{Argumentação como Diálogo entre Opostos}

A argumentação é aqui entendida como uma atividade de natureza social e discursiva na qual indivíduos que expressam pontos de vista divergentes sobre um tema defendem suas posições com vistas a torná-las aceitáveis aos seus interlocutores (Van Eemeren \& cols., 1996). Dois aspectos dessa definição merecem destaque. O primeiro é que a argumentação é uma atividade inerentemente dialógica. Entretanto, no sentido em que aqui é empregada, a palavra diálogo não deveria ser entendida em sua acepção mais corriqueira, qual seja, a de uma interação verbal que se realiza face-a-face. $\mathrm{O}$ entendimento da natureza da atividade argumentativa exige que se supere essa definição mais restritiva e se conceba diálogo essencialmente como um "espaço de tensão" (expressão tomada de Faraco, 2003, p. 67) entre perspectivas, não necessariamente entre indivíduos, que se confrontam e respondem uma à outra. Na perspectiva adotada no presente trabalho, o diálogo (no sentido sugerido acima) é o modelo que define a estrutura e o funcionamento da argumentação, quer esta ocorra em situações de interação face-a-face, em situações solitárias (como ocorre freqüentemente na escrita) ou mesmo na forma privada do pensamento não expresso. Nesses dois últimos casos, "vozes" (no sentido bakhtiniano de termo, Wertsch, 1991) de oposição comparecem à argumentação à medida que o proponente de um argumento antecipa e responde a perspectivas alternativas e críticas que poderiam ser levantadas em relação às posições que defende. A ênfase sobre oposição e divergência remete ao segundo aspecto que se deseja ressaltar na definição acima, qual seja, a natureza dialética da argumentação (Freeman, 1991; Van Eemeren \& cols., 1996). O argumentar só se torna pertinente em situações em que o indivíduo defende um ponto de vista contra o "pano de fundo" constituído por perspectivas alter- nativas, oposição e reações críticas da parte de um oponente, real ou potencial.

\section{Argumentação da Criança}

Estudos que investigam a argumentação infantil mostram que o percurso que possibilita à criança o manejo da estrutura dialógico-dialética da argumentação é marcado por duas importantes assimetrias. A primeira refere-se à hipótese de que as condutas de justificação de pontos de vista emergiriam mais cedo no desenvolvimento ontogenético da criança, se comparadas ao manejo discursivo de ponto de vista alternativos e contra-argumentos (por ex.: De Bernardi \& Antolini, 1996; Golder \& Coirier, 1994, 1996; Leitão \& Banks-Leite, 2006) embora, menos freqüentemente, alguns autores têm postulado um desenvolvimento precoce das condutas opositivas (Ferreira, 2005; Orsolini \& Pontecorvo, 1992; Pontecorvo, 1987; Stein, Bernas, Calicchia \& Wright, 1996; Stein \& Miller, 1993). A segunda assimetria torna-se visível na comparação entre a argumentação oral e a escrita gerada por crianças. Em contraste com a aparente facilidade com que crianças justificam pontos de vista e lidam com oposição em situações de interação oral, a realização das mesmas operações em textos escritos parece ser tarefa consideravelmente mais árdua (De Bernardi \& Antolini, 1996; Dolz, 1996; Golder \& Coirier, 1996; Santos \& Vasconcelos, 1997).

Na tentativa de entender dificuldades encontradas pelas crianças, na produção da escrita argumentativa, variados fatores têm sido enfatizados. Aspectos pragmáticos (por ex., como, porque, para quê e em que situação a argumentação é produzida), cognitivos (por ex., dificuldade de articular posições opostas no âmbito de um mesmo texto) e relativos ao funcionamento da língua (manejo de segmentação e integração de sentenças, construção da coesão textual, monitoramento da clareza, consistência e coerência informacional do texto, entre outros) estão entre os fatores freqüentemente investigados. Proceder a uma revisão extensiva das variadas hipóteses levantadas a esse respeito é algo que fugiria ao escopo do presente trabalho (ver Leitão, 2001, para uma breve revisão desses aspectos). Uma hipótese, entretanto, interessa examinar mais de perto: a que remete ao papel que a consciência da "estrutura prototípica" da argumentação teria no processo de produção de argumentativa.

\section{Consciência Metatextual}

Atribui-se geralmente a Gombert (1992) o mérito de ter introduzido na literatura o termo metatextual para designar um tipo particular de funcionamento metalingüístico dos indivíduos (os elementos incluídos nesta seção foram adaptados de Spinillo \& Simões, 2003, no qual os interessados poderão encontrar uma revisão de estudos sobre o tópico). Por metalingüístico entenda-se aqui um tipo de funcionamento cognitivo-discursivo que permite aos indivíduos tomarem a língua, não apenas como recurso simbólico que possibilita a produção de sentidos sobre fenômenos do mundo físico e social, mas, também, como alvo de reflexão e análise em diferentes níveis: o fonêmico (caso em que se falaria de uma consciência fonológica), o lexical (consciência metalexical), 
o frasal (consciência sintática), o pragmático (consciência pragmática).

Aos diferentes níveis acima citados, Gombert (1992) acrescenta o da consciência_metatextual na qual o texto, em sua inteireza, se torna alvo de atenção e reflexão tanto em seus aspectos micro-lingüísticos (emprego de coesivos, pontuação, etc.) como nos macro-lingüísticos (análise dos conteúdos presentes nos textos, reflexão sobre formas lingüísticas e elementos que caracterizam diferentes tipos de textos, etc.). Ao presente estudo interessou de modo específico investigar a possível relação entre a consciência dos constituintes básicos da argumentação, um aspecto que remete ao plano macro-lingüístico da consciência metatextual, e a tendência a incluir tais elementos em textos efetivamente produzidos.

\section{Método}

\section{Participantes}

Sessenta alunos participaram deste estudo: 20 da segunda e 20 da quinta série do Ensino Fundamental além de 20 estudantes do primeiro ano de cursos universitários diversos (tomados como grupo de referência para a análise dos dados das crianças), todos oriundos de instituições da rede privada de ensino.

\section{Procedimento}

Todos os participantes do estudo foram observados a partir de duas atividades: uma de julgamento (com a qual se procurou favorecer uma tomada de consciência dos constituintes da "estrutura prototípica" da argumentação e de sua finalidade persuasiva) e outra de produção textual. Para metade dos participantes, aleatoriamente definida, a atividade de julgamento precedeu a de produção, o inverso ocorrendo com a outra metade.

$\mathrm{Na}$ atividade de julgamento, solicitou-se individualmente a cada participante que lesse sucessivamente quatro diferentes versões de um pequeno texto produzido para fins específicos da pesquisa e julgasse a adequação de cada uma delas tendo em vista a finalidade comunicativa do texto: tornar aceitável o ponto de vista do autor. O texto, que era apresentado aos participantes como uma tentativa de convencer a diretora de uma escola a aumentar o tempo de recreio, começava com uma pequena introdução ao tema seguida de um ponto de vista ("Eu acho que o tempo do recreio devia ser aumentado") e uma justificativa ("porque mal dá tempo para lanchar"). Na seqüência, a posição supostamente defendida pela escola era referida, na forma de um contra-argumento ("A escola diz que se aumentar o tempo não vai dar para passar a matéria toda do ano"). O texto concluía com uma refutação do contra-argumento e conseqüente restauração da força do ponto de vista inicial ("mas isso não é verdade porque se a professora for boa, ela conseguirá passar a matéria toda"). Os diferentes elementos do texto eram apresentados em pequenos cartões, de cores e tamanhos variados, que se encaixavam como num quebracabeça. O jogo de retirada e inserção de diferentes "peças" do quebra-cabeça, executado pela pesquisadora, permitia que fossem apresentadas aos participantes quatro versões do texto: 1) introdução e ponto de vista (doravante $\mathrm{I}+\mathrm{PV}$ ); 2) introdução, ponto de vista e justificativa $(\mathrm{I}+\mathrm{PV}+\mathrm{J}) ; 3)$ introdução, ponto de vista, justificativa e contra-argumento $(\mathrm{I}+\mathrm{PV}+\mathrm{J}+\mathrm{C})$ e 4) introdução, ponto de vista, justificativa, contra-argumento e resposta ao contra-argumento/conclusão (I+PV+J+C+R).

A título de controle, apresentava-se ainda aos participantes um segundo texto, cujo tema era idêntico ao do referido acima, mas, no qual não aparecia nenhum dos elementos tipicamente constituintes das seqüências argumentativas (texto não argumentativo, doravante TNA). Com a inclusão desse texto procurou-se investigar se o tamanho do texto, e não a presença/ausência de elementos com diferentes funções argumentativas, seria um critério utilizado pelas crianças na análise das diferentes versões textuais. A ordem de apresentação das várias versões foi definida de modo a que versões menos e mais extensas fossem alternadamente apresentadas. Com isso buscouse evitar que o acréscimo gradual de novos elementos ao texto fosse tomado pelos participantes como critério de completude e, portanto, de maior qualidade do texto. A apresentação das várias versões deu-se na seguinte ordem: $(\mathrm{I}+\mathrm{PV}+\mathrm{J}),(\mathrm{I}+\mathrm{PV}),(\mathrm{I}+\mathrm{PV}+\mathrm{J}+\mathrm{C}+\mathrm{R}),(\mathrm{I}+\mathrm{PV}+\mathrm{J}+\mathrm{C})$, (TNA). Na ocasião em que uma nova versão era apresentada, chamava-se a atenção dos participantes para a diferença entre as versões anteriormente apresentadas e a versão correntemente considerada bem como para o propósito persuasivo do texto. As versões já avaliadas permaneciam diante dos participantes durante toda a atividade. Uma vez analisadas todas as versões, pediase ainda a cada participante que indicasse qual delas lhe parecia a mais adequada, tendo em vista o propósito último do texto.

$\mathrm{Na}$ atividade de produção textual, solicitou-se aos participantes que escrevessem suas opiniões a respeito do tempo destinado ao recreio na escola a que pertenciam, se deveria, ou não, ser aumentado. A atividade era proposta aos alunos como sendo parte de um levantamento das opiniões dos alunos daquela escola a respeito desse tema. A instrução dada imediatamente antes da produção do texto enfatizava o propósito persuasivo do mesmo: convencer o leitor da plausibilidade da posição defendida.

\section{Resultados}

Os dados obtidos foram analisados em relação a dois fatores: a atenção dada pelos participantes aos elementos constitutivos da "estrutura argumentativa" ao julgarem a eficácia persuasiva das várias versões textuais e a presença/ ausência desses mesmos elementos nos textos que produziram.

\section{Julgando a eficácia persuasiva do texto: critérios utilizados}

Da análise dos elementos sobre os quais os participantes focavam sua atenção ao julgarem a adequação das várias versões à finalidade persuasiva do texto, três categorias surgiram. 


\section{Foco sobre a dimensão polifônica.}

Por foco sobre a dimensão polifônica entenda-se aqui a referência, direta ou indireta, à presença/ausência de elementos contrários à posição defendida numa dada versão textual (vozes de oposição), como critério para avaliação de se a referida versão seria ou não adequada à consecução do objetivo comunicativo do texto (convencer). O exemplo 1 abaixo ilustra esse caso (nos exemplos apresentados doravante, "P" e "E" indicam falas dos participantes e da experimentadora, respectivamente. Grifos assinalam elementos destacados na análise).

Exemplo 1 (P1, $5^{\mathrm{a}}$ série)

1. (P1 lê em voz alta a versão $\mathrm{I}+\mathrm{P}+\mathrm{J}+\mathrm{C}$ já analisada por ele) E: E agora, P1, ele [o

2. escritor do texto] colocando essa última frase ao contra-argumento: "mas isso

3. não é verdade porque se a professora for boa, ela conseguirá passar a matéria

4. toda", vai convencer a direção do que ele quer?

5. P1: Convence

6. E: Por que?

7. P1: Porque aqui, além dele explicar, ele ainda diz o pensamento... é... ele ainda

8. dá uma justificativa de não aumentar... porque não aumenta o tempo. E

9. além do que a justificativa dele pra aumentar, tem a justificativa da outra

10. pessoa que não quer que aumente

11. E: Sei, então é importante pra convencer que ele coloque a justificativa de outra

12. pessoa que pense diferente dele?

13. P1: Também, pra pessoa que ler aquilo poder avaliar tanto uma quanto a outra

$\mathrm{O}$ extrato acima mostra a clareza de $\mathrm{P} 1$ quanto à existência de oposição entre posições que aparecem no texto (linhas 7-10). Isto, por si só, já evidencia sua atenção para o que aqui se denomina dimensão polifônica do texto. Se alguma dúvida houvesse quanto a se a presença de vozes opostas é a dimensão do texto sobre a qual P1 concentra sua atenção ao julgá-lo um texto "convincente", a mesma se dissiparia com a explicitação que aparece na linha 13.

\section{Foco sobre a dimensão justificatória.}

O que dá coerência aos casos deste tipo é que, em todos eles, a atenção dos participantes se volta para a presença/ ausência de elementos que fortalecem o ponto de vista do autor. Ou seja, o aspecto que, para os participantes, ajuda a tornar o texto persuasivo é a elaboração da estrutura de justificação do texto.

\section{Exemplo 2 (P2, 5a. série)}

1. (P2 lê a versão I+P+J já avaliada) E: Pronto. Aí você veja, $\mathrm{P} 2$, ele [escritor]

2. construiu esse texto e eu queria saber o que é que você achou dessa maneira
3. que ele construiu. Você acha que assim ele vai convencer a direção a fazer o

4. que ele quer?

5. $\mathrm{P} 2$ : Hum, acho que não

6. E: Por que não?

7. $\mathrm{P} 2$ : Ah, porque assim... pra lanchar assim... porque tem mais coisas pra fazer no

8. recreio, ele só botou pra lanchar, aí...

9. E: Você acha que o porquê que ele colocou foi pouco, é isso?

10. P2: Foi

11. E: Ele deveria ter colocado mais porquês, é isso?

12. P2: Foi

13. E: Então você acha que não convence porque ele não colocou mais porquês?

14. P2: É... porque eu acho que dá tempo, né, de lanchar... no tempo, mas assim...

15. porque tem mais coisas pra fazer, aí ele botou só... isso. Aí, eu acho que não dá

16. E: Agora, então, você não concorda com o porquê dele ou você não concorda

17. com a quantidade dos porquês?

18. P2: Eu não concordo com a quantidade dos porquês

O extrato acima deixa claro (linhas $7-8,18)$ que o critério adotado por P2 para considerar "não convincente" a versão avaliada é o número insuficiente de justificativas nela apresentadas. Ainda que o dito nas linhas 14-15 pareça focalizar o conteúdo da justificativa apresentada pelo escritor, do qual P2 discorda, não é a discordância em relação a esse conteúdo que pesa em seu julgamento e, sim, o fato de que outras justificativas deixaram de ser incluídas.

\section{Foco sobre aspectos extratextuais.}

Agrupados nessa seção estão os casos em que o julgamento a respeito da adequação do texto à sua função comunicativa tomava como critério aspectos que não diziam respeito a qualquer dos elementos do "esquema" argumentativo, nem a qualquer outro aspecto diretamente relacionado à argumentação produzida no texto. Por exemplo: o acordo ou desacordo do participante com a posição defendida no texto, o tamanho do mesmo, opiniões do participante sobre experiências vividas na escola, etc. $\mathrm{O}$ caso abaixo ilustra o julgamento baseado em aspectos extratextuais. Nele, o elemento focalizado pelo participante ao considerar "não convincente" a versão em pauta é a percepção que parece ter do papel social do destinatário do texto e dos atributos que tal papel lhe conferem. A diretora (vista como "dona" da escola, linhas 7-8) aparece investida de autoridade, de um poder de decisão acima de qualquer argumento.

Exemplo 3 (P3, 2 ${ }^{\mathrm{a}}$ série)

1. (P3 lê a versão I+P+J já avaliada) E: Aí você veja, $\mathrm{P} 3$, dessa maneira que ele

2. construiu, ele deu a opinião dele, como eu lhe falei, ele quer que aumente e ele

3. explicou porquê. Porque ele disse que mal dá tempo pra lanchar. Essa maneira 
4. que ele construiu, você acha que convence a diretora a aumentar?
5. P3: Não
6. E: Por que?
7. P3: Porque a diretora... ela... ela é dona do colégio, então ela acha que o tempo

8. não deve aumentar

A Figura 1 mostra o percentual de casos em que cada um dos critérios acima foi empregado nos 100 julgamentos analisados (20 indivíduos em cada grupo avaliaram, cada um, cinco versões textuais). Note-se, entretanto, que a apresentação desses percentuais tem aqui um propósito eminentemente descritivo uma vez que a investigação da natureza dos critérios adotados (ênfase qualitativa), e não a comparação das

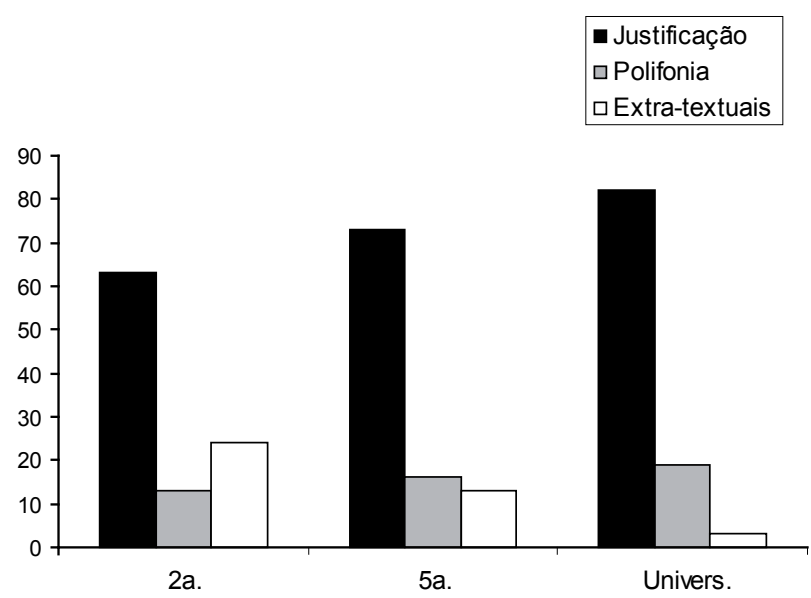

Figura 1. Percentual de utilização de diferentes critérios de julgamento, por grupo.

freqüências de emprego de diferentes critérios pelos grupos, foi o objetivo básico da análise em questão.

A distribuição dos valores indicados na Figura 1 mostra que, independente de se uma dada versão era avaliada como convincente ou não, participantes de todos os grupos concentraram sua atenção primordialmente sobre elementos de fortalecimento do ponto de vista quando avaliavam e refletiam sobre a eficácia persuasiva do texto. Entretanto, um dos resultados mais interessantes obtidos nessa primeira análise, não refletido na figura acima, apareceu quando se olhou mais de perto para variações qualitativas nas respostas dos participantes. Na avaliação da versão em que um contra-argumento não refutado aparece $(\mathrm{I}+\mathrm{PV}+\mathrm{J}+\mathrm{C}), 55 \%$ dos alunos da segunda série, $45 \%$ dos da quinta e $50 \%$ dos universitários referiam-se à presença de contra-argumento como um obstáculo para que o texto atingisse sua finalidade persuasiva. Um outro aspecto interessante observado foi que, enquanto nenhum dos alunos da segunda série considerou que a antecipação de contra-argumento seria algo relevante na composição das versões avaliadas, $20 \%$ dos alunos da quinta série e $40 \%$ dos universitários a consideraram pertinente baseados na idéia de que o estabelecimento de um confronto de posições é importante em um texto que visa ao convencimento. Embora escassos, esses casos apontaram para a consciência desses indivíduos do valor retórico da contraargumentação (Leitão, 2003), ou seja, seu reconhecimento de que a consideração de elementos de oposição ao ponto de vista defendido pode ser posta 'a serviço' da finalidade última do texto.

Para investigar, de modo sistemático, em que medida a antecipação de contra-argumento era vista como relevante, ou não, para a argumentação criada no texto, uma segunda análise foi realizada, dessa feita focalizando exclusivamente as respostas dos participantes quando indagados sobre qual dentre as versões avaliadas lhes parecia a mais adequada

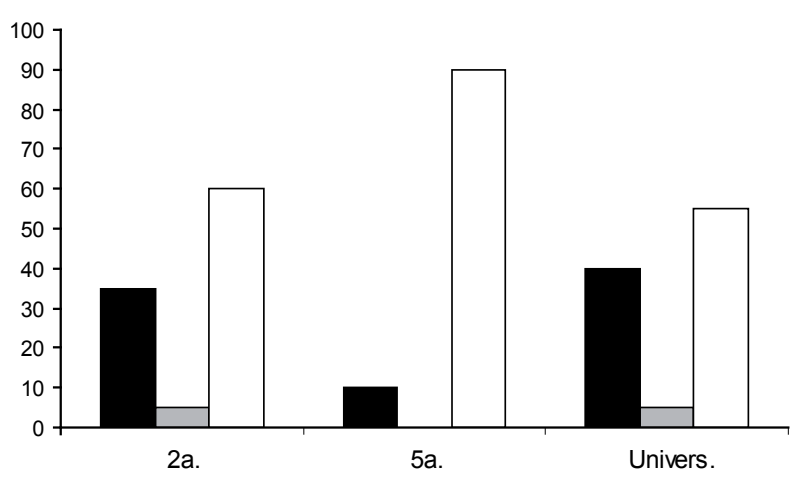

Figura 2. Identificação da "versão textual mais adequada", por grupo.

tendo em vista o objetivo persuasivo do texto. A Figura 2 sumaria os resultados dessa análise.

O interessante a notar nos dados apresentado na Figura 2 acima é que a justificação do ponto de vista é o aspecto que se ressalta nas versões consideradas mais convincentes por todos os grupos, embora apenas na quinta série a preferência por $(\mathrm{I}+\mathrm{PV}+\mathrm{J}+\mathrm{C}+\mathrm{R})$ em relação a $(\mathrm{I}+\mathrm{PV}+\mathrm{J})$ seja significativamente maior (Qui-quadrado, $X^{2}=12,8, g l=1, p<0,0005$, unicaudal). $\mathrm{Em}(\mathrm{I}+\mathrm{PV}+\mathrm{J})$ a ênfase na justificação é óbvia. Em $(\mathrm{I}+\mathrm{PV}+\mathrm{J}+\mathrm{C}+\mathrm{R})$, ainda que um contra-argumento seja referido, a resposta, como indicado anteriormente, é vista pelos participantes como elemento capaz de restabelecer a força do argumento inicial. Portanto, uma vez mais, a justificação do ponto de vista aparece como o elemento que, em última instância, confere ao texto seu efeito persuasivo. Nenhum caso foi anotado em que as versões (I+PV) e (TNA) tenham sido escolhidas.

Os resultados acima permitem ainda que se conclua que o tamanho do texto não parece ter tido qualquer efeito sobre os julgamentos feitos pelos participantes. Dois elementos dão sustentação a essa conclusão $O$ primeiro é que em nenhum caso a versão (TNA) foi apontada como a mais convincente, embora fosse tão extensa quanto a versão mais escolhida $(\mathrm{I}+\mathrm{PV}+\mathrm{J}+\mathrm{C}+\mathrm{R})$. Soma-se a isso o fato de um número expressivo de participantes ter considerado a versão $(\mathrm{I}+\mathrm{PV}+\mathrm{J})$, a segunda menor dentre as avaliadas, adequada ao propósito persuasivo do texto. Finalmente, uma observação curiosa que 
resultou dessa análise foi que, em todas as séries, a rejeição à versão $(\mathrm{I}+\mathrm{PV}+\mathrm{J}+\mathrm{C})$ deveu-se primordialmente à percepção do elemento de oposição como obstáculo para alcance do objetivo do texto.

Para examinar, ainda mais de perto, a forma como os participantes entendiam o papel da contra-argumentação, as avaliações que os mesmos realizaram sobre versões que incluíam contra-argumento foram detalhadamente analisadas. Para tanto, foram computados todos os casos em que, ao avaliarem essas versões, os participantes se referiam explicitamente à presença do contra-argumento como algo que favorecia ou dificultava o alcance da finalidade persuasiva do texto. Os resultados obtidos mostraram que $90 \%$ dos alunos da segunda série, $69 \%$ dos da quinta-série e $56 \%$ dos universitários consideraram que a antecipação de contraargumentos dificultava o convencimento do leitor. Além disso, esses resultados refletem uma importante variação intragrupo, encontrada entre os participantes de todos os níveis de escolaridade pesquisados, quanto ao efeito atribuído à contra-argumentação. Embora somente na segunda série a diferença entre os percentuais de indivíduos que atribuem efeito negativo ao contra-argumento $(90 \%)$ e os que não o fazem varie significativamente (Qui-quadrado, $X^{2}=8,33$; $g l=1 ; p<0,005)$, é justamente a falta de predominância de uma ou outra tendência o que chama a atenção nessa análise. É curioso observar que, mesmo entre os universitários, aproximadamente metade dos participantes $(56 \%)$ percebe a antecipação de contra-argumento como um elemento que pode dificultar o alcance do objetivo persuasivo do texto. Uma hipótese que se pode levantar é que a percepção do papel do contra-argumento possa ter um impacto sobre o manejo de elementos dessa natureza nos textos que os indivíduos produzem. Para investigar essa possibilidade, de forma mais detalhada, duas outras análises foram realizadas.

\section{Justificando posições e antecipando oposição num texto de opinião}

Inicialmente, todas as produções escritas dos participantes foram analisadas em função da presença de ponto de vista, justificativas, antecipação de contra-argumento e resposta ao contra-argumento. Quatro juízes participaram dessa análise obtendo-se um índice final de acordo da ordem dos $82 \%$. A título de ilustração das análises realizadas, um dos textos analisados é transcrito e comentado em seguida. Características das produções dos participantes são preservadas. Números, em parênteses, marcam o início de novas linhas no original.

\section{Exemplo 4 (H.N.S.B.S, $2^{\mathrm{a}}$ série)}

(1) eu ajo que o recreio deve aumenta porque nos (2) devemos ter mais tempo para brinca no colégio (3) mais o meu outro amigo diz que o recreio não deve (4) aumenta porque ele faz tudo que ele gosta na hora do recreio (5) Já eu não

Todos os elementos básicos constitutivos da seqüência argumentativa (ponto de vista, justificativa, contra-argumento, resposta) são facilmente identificados no texto acima. Já na primeira linha $\mathrm{H}$ formula um ponto de vista favorável ao aumento do tempo destinado ao recreio. A justificativa para essa posição é dada em seguida (linhas 1-2). Na linha 3, a posição oposta a seu ponto de vista aparece na voz de um amigo que contra-argumenta afirmando que, pelo menos, para ele (o amigo), o tempo é suficiente para fazer tudo o que gosta (linha 4). O texto se encerra com uma resposta ao contraargumento que implicitamente reafirma a posição inicial da escritora: o fato do tempo do recreio ser considerado o bastante pelo "amigo" não o torna bastante para a escritora. Cabe ao leitor concluir que, portanto, a defesa do aumento do tempo de recreio ainda se justifica. Análises semelhantes foram realizadas em todos os textos produzidos. A Figura 3

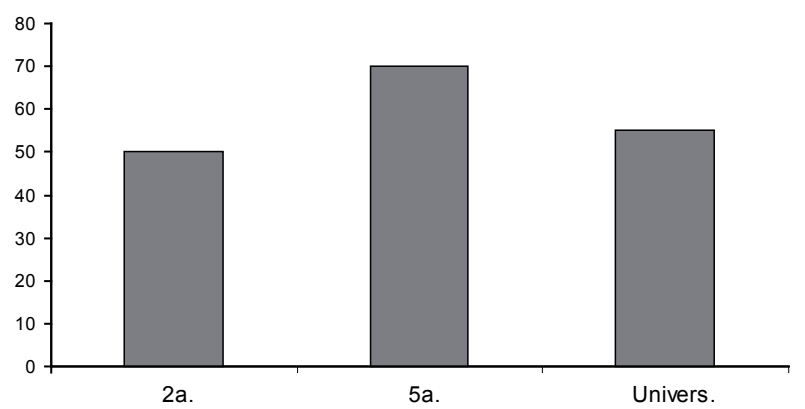

Figura 3. Percentual de textos contendo diferentes elementos da "estrutura argumentativa".

mostra a distribuição dos elementos analisados nos textos produzidos por diferentes grupos.

A frequiência com que cada elemento aparece nas produções de todos os grupos reflete o valor atribuído pelos participantes à definição e justificação de pontos de vista na escrita do texto em questão. Em apenas quatro dos textos analisados não se pode identificar algum tipo de justificativa para as posições defendidas. Situação diferente se pode observar, entretanto, no que se refere à antecipação de objeções às posições do autor. Possíveis contra-argumentos para a posição do autor aparecem em apenas $45 \%$ dos textos da segunda série, atingindo a marca de $70 \%$ e $75 \%$ na quinta série e entre os universitários, respectivamente. Diferenças nos percentuais registrados entre os grupos não alcançaram níveis de significância quando tratados com o Qui-quadrado. Esse resultado não requer, entretanto, maiores considerações uma vez que, como anteriormente referido, a comparação entre os grupos quanto à frequiência de ocorrência dos elementos aqui tratados não era um objetivo do estudo. Tal análise foi aqui tratada como uma etapa preliminar necessária à análise de uma das questões centrais do presente estudo, qual seja, a da existência de uma possível relação entre os elementos que os participantes consideravam relevantes quando julgavam diferentes versões textuais e os incluídos nos textos que eles próprios produziram.

\section{Relacionando julgamentos e produções textuais}

Uma vez que ponto de vista e justificativa apareceram em praticamente $100 \%$ dos textos produzidos pelos participan- 
tes e estiveram presentes em todas as versões consideradas convincentes, a análise apresentada nessa seção focalizou apenas o manejo da contra-argumentação nas avaliações e produções textuais realizadas pelos participantes. A pergunta a que se procurou responder com essa análise foi se haveria consistência entre os julgamentos feitos quanto à relevância da contra-argumentação (sua presença ou ausência) nas várias versões textuais avaliadas e a antecipação de contra-argumentos nos textos produzidos. Para investigar essa possível relação, quatro categorias foram geradas: 1) O participante considera mais convincente o texto que antecipa contra-argumentos e ele próprio os antecipa no texto que produz. 2) $\mathrm{O}$ participante considera mais convincente o texto que antecipa contra-argumentos, mas não os antecipa no texto que produz. 3) O participante considera mais convincente o texto que não antecipa contra-argumentos, mas ele próprio os antecipa no texto que produz. 4) $\mathrm{O}$ participante considera mais convincente o texto que não antecipa contra-argumentos e não antecipa elementos dessa natureza no texto que produz. A Figura 4 mostra o percentual de casos em que uma consistência julgamento/ produção foi observada (categorias 1 e 4 acima).

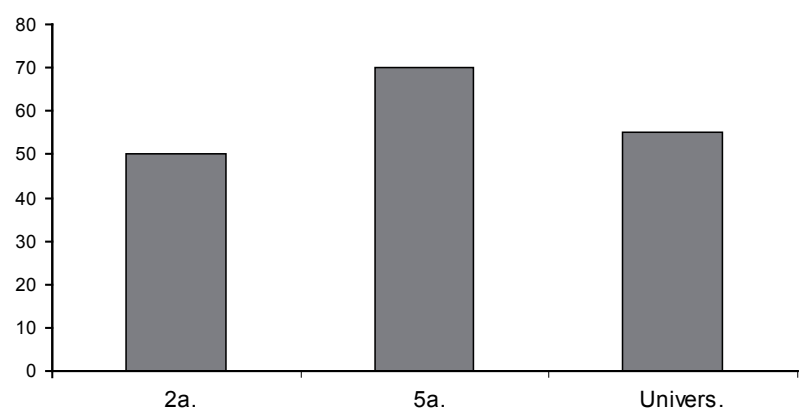

Figura 4. Percentual de casos de consistência julgamento-produção observados, por grupo.

Os dados apresentados na Figura 4 mostram que em apenas metade dos casos, aproximadamente ( $50 \%$ na segunda série, $70 \%$ na quinta e $55 \%$ entre os universitários), a ênfase nos elementos de oposição aparece de forma consistente nas atividades de julgamento e produção textual. Para os casos restantes, tal consistência não foi observada. Note-se que, mesmo na quinta série, grupo no qual a relação entre julgar e produzir foi mais notável, as diferenças entre casos de consistência (categorias 1 e 4 acima) e de inconsistência (categorias 2 e 3) não foram significativas (prova de McNemar). Tal observação sugere, portanto, que a consciência dos elementos constitutivos de "esquema argumentativo" (facilitada pela atividade de avaliação das diferentes versões textuais) não parece ter de fato qualquer relação sistematicamente observável com a propensão dos indivíduos a incluírem aqueles elementos em suas produções textuais. Nenhuma relação foi igualmente observada entre a ordem em que julgamento e produção foram realizadas pelos participantes (para metade deles o julgamento precedeu a produção) e a tendência a incluir, ou não, os diversos elementos da "estrutura argumentativa" nos textos produzidos.

\section{Discussão}

O propósito geral desse estudo foi explorar em que medida a consciência que os indivíduos possuem da "estrutura argumentativa prototípica" (justificação de pontos de vista, consideração de posições contrárias) se relacionaria com a produção daquela estrutura em textos por eles produzidos. Quais são os pontos importantes dos resultados obtidos?

\section{De que elementos é constituído um “bom” texto argumentativo?}

A presença de justificativas para um ponto de vista foi considerada por participantes de todos os grupos, como o elemento central, indispensável à estrutura de um texto que visa ao convencimento do leitor. Das várias versões avaliadas, as sequiências formadas por introdução, ponto de vista e justificativa $(\mathrm{I}+\mathrm{P}+\mathrm{J})$ ou introdução, ponto de vista, justificativa, contra-argumentos e resposta $(\mathrm{I}+\mathrm{P}+\mathrm{J}+\mathrm{C}+\mathrm{R})$ foram praticamente as únicas consideradas "suficientemente boas" para que o texto pudesse alcançar sua finalidade persuasiva. O mesmo não ocorreu com versões contendo sequiências do tipo $(\mathrm{I}+\mathrm{P})$ e $(\mathrm{I}+\mathrm{P}+\mathrm{J}+\mathrm{C})$, ambas vistas como inadequadas em relação ao alcance da finalidade comunicativa do texto.

Em contraste com a ênfase dada à justificação de pontos de vista, a antecipação de possíveis contra-argumentos para o ponto de vista defendido no texto foi vista, freqüentemente, como um possível obstáculo para a consecução da finalidade persuasiva do discurso, com exceção dos casos em que aqueles eram, de imediato, refutados. Essa tendência foi particularmente registrada entre as crianças da segunda série. Quando avaliavam a adequação das diferentes versões textuais utilizadas no estudo, a retirada do elemento de oposição ao ponto de vista do texto era vista, em geral, como uma estratégia desejável para que o texto se tornasse convincente. Uma diferença qualitativa considerada relevante entre esses alunos e os dos demais grupos observados é que nesses últimos a antecipação de contra-argumento ora era vista como obstáculo à persuasão, ora como elemento importante em um texto com o qual se pretende convencer. Tomados em conjunto, tais resultados foram considerados indicativos de que a contra-argumentação, enquanto tal, não é necessariamente concebida como uma estratégia relevante à produção de textos argumentativos. A avaliação de sua pertinência parece antes sujeita a considerações de natureza pragmática relativas ao impacto que a antecipação de contra-argumentos poderia ter para o alcance do objetivo persuasivo do texto (Leitão, 2003).

\section{De volta à controvérsia: "esquemas prototípicos" orientam a produção textual?}

A pergunta central que o presente estudo pretendeu explorar foi quanto à possível relação entre a consciência metatextual dos participantes, aqui definida como consciência dos constituintes básicos do chamado "esquema argumentativo prototípico", e a tendência dos mesmos a incluírem tais constituintes nos textos que produziam. A resposta a essa questão pode ser dada partir da consideração 
da freqüência com que se registrou uma consistência entre os elementos que um indivíduo considerava relevantes quando avaliava diferentes versões textuais e os que incluía no texto que escrevia. A observação de casos de consistência versus casos de inconsistência em cada grupo não autoriza, entretanto, a conclusão de que julgamento e produção textuais teriam sido regidos pelo mesmo critério de valoração (ou subvaloração) de um dado componente do "esquema argumentativo". À valoração de um dado elemento na atividade de avaliação (por ex., ênfase na dimensão justificatória) nem sempre correspondeu a valoração do mesmo elemento na atividade de produção textual (inclusão de justificativa) e vice-versa. Tais resultados abrem, portanto, espaço para a consideração de outros fatores, que não estritamente a consciência do "esquema argumentativo", na decisão do escritor de incluir, ou não, num texto qualquer dos elementos teoricamente definidos como parte do "esquema argumentativo prototípico".

Neste sentido, um resultado particularmente interessante desse estudo foi o obtido com a análise do papel que os participantes atribuem à contra-argumentação num texto que visa ao convencimento do destinatário. A idéia de que antecipar contra-argumentos pode contribuir negativamente para o alcance da finalidade persuasiva do texto dá margem a que se considere o impacto que aspectos das situações em que se produz argumentação (dentre os quais o objetivo persuasivo é de especial importância) exerce sobre a decisão do escritor de incluir, ou não, um dado elemento da "estrutura argumentativa" num texto que produz. A decisão de trazer para o texto elementos de oposição dependeria, portanto, de um tipo de consciência retórica (Leitão, 2003) que permita ao escritor avaliar antecipação/rebatimento de contra-argumentos como estratégia que pode ser retoricamente efetiva no alcance do propósito persuasivo do texto.

\section{Referências}

Adam, J-M. (1992). Les textes: types et prototypes. Paris: Nathan.

Brassart, D. G. (1996). Does a prototypical argumentative schema exist? Argumentation, 10(2), 163-174.

Bronckart, J-P. (1999). Atividade de linguagem, textos e discursos. Por um interacionismo sócio-discursivo. São Paulo: EDUC.

Coirier, P., Andriessen, J. \& Chanquoy, L. (1999). From planning to translating: The specificity of argumentative writing. Em G. Rijlaarsdam \& E. Espéret (Orgs. da série) e J. Andriessen \& P. Coirier (Orgs. do vol.), Studies in writing, Vol 5: Foundations of argumentative text processing (pp. 1-28). Amsterdã: Amsterdam University Press.

Coirier, P., Pouit, D. \& Golder, C. (2000, setembro). Argumentative schema: a relevant tool when analysing the writing processes? Trabalho apresentado em Reunião Bienal (Biennial Meeting) da European Association for Research on Learning and Inbstruction. - Special Interest Group/Writing, Writing Conference 2000 - Workshop on Argumentative Text Processing, Verona, Itália.

De Bernardi, B. \& Antolini, E. (1996). Structural differences in the production of written arguments. Argumentation, 10(2), 175-196.
Dolz, J. (1996). Learning argumentative capacities. A study of the effects of a systematic and intensive teaching of argumentative discourse in 11-12 year old children. Argumentation,10(2), 227-251.

Faraco, C. A. (2003). Linguagem \& diálogo-as idéias lingüísticas do Círculo de Bakhtin. Curitiba: Criar Edições.

Ferreira, A. P. M. (2005). O desenvolvimento de condutas opositivas em crianças: antecipação de posições contrárias. Dissertação de Mestrado, Universidade Federal de Pernambuco, Recife.

Freeman, J. B. (1991). Dialectics and the macrostructure of arguments. Berlim: Foris.

Golder, C. \& Coirier, P. (1994). Argumentative text writing: Developmental Trends. Discourse Processes, 18, 187-210.

Golder, C. \& Coirier, P. (1996). The production and recognition of typological argumentative text markers. Argumentation, 10(2), 271-282.

Gombert, J. E. (1992). Metalinguistic Development. Harvester: Wheatsheaf.

Leitão, S. (2001). Composição textual: especificidade da escrita argumentativa. Em J. Correa, A. Spinillo \& S. Leitão (Orgs.), Desenvolvimento da linguagem: escrita e textualidade (pp. 117-141). Rio de Janeiro: Nau Editora/FAPERJ.

Leitão, S. (2003). Evaluating and selecting counterarguments. Studies of children's rhetorical awareness. Written Communication, 20(3), 269-306.

Leitão, S. \& Banks-Leite, L. (2006). Argumentação na linguagem infantil: algumas abordagens. Em A. Del Ré (Org.), Introdução à psicolingüística: a aquisição de linguagem. São Paulo: Contexto.

Orsolini, M. \& Pontecorvo, C. (1992). Children's talk in classroom discussions. Cognition and Instruction, 9(2), 113-136.

Perelman, C. \& Olbrecht-Tyteca, L. (1996). Tratado de argumentação: a nova retórica ( $2^{\mathrm{a}}$ ed., M. E. G. G. Pereira, Trad.). São Paulo: Martins Fontes (Trabalho original publicado em 1958)

Pontecorvo, C. (1987). Discussing for reasoning: The role of argument in knowledge construction. Em E. de Corte, H. Lodewijks, R. Parmentier \& P. Span (Orgs.), Learning and instruction. European research in the international context, Vol. 1 (pp. 239-250). Oxford/Leuven: Pergamon/Leuven University Press.

Rego, L. L. B. (2005). Um estudo exploratório dos critérios utilizados pelas crianças para definir histórias. Em M. G. Dias \& A. G. Spinillo (Orgs.), Tópicos em Psicologia Cognitiva (pp. 117-133). Recife: Editora Universitária da UFPE.

Santos, S. L. \& Vasconcelos, S. B. de A. (1997, setembro). The impact of text structure on children's argumentative writing. Trabalho apresentado em Teaching and learning argument $-2^{\text {nd }}$ International Conference, Londres, Inglaterra.

Spinillo, A. G. \& Simões, P. U. (2003). O desenvolvimento da consciência metatextual em crianças: questões conceituais, metodológicas e resultados de pesquisas. Psicologia: Reflexão e Crítica, 16(3), 537-546.

Stein, N. L. (1988). The development of children's storytelling skill. Em M. Franklin \& S. Barten (Orgs.), Child language (pp. 262-279). New York: Oxford University Press.

Stein, N. L., Bernas, R. S., Calicchia, D. J. \& Wright, A. (1996). Understanding and resolving arguments: The dynamics of negotiation. Em B. Britton e A. G. Graeser (Orgs.), Models of understanding text (pp. 257-287). Hillsdale: Erlbaum. 
Stein, N. L. \& Miller, C. A. (1993). The development of memory and reasoning skills in argumentative contexts: Evaluating, explaining, and generating evidence. Em R. Glaser (Org.), Advances in instructional psychology, Vol 4 (pp. 285-325). Hillsdale: Erlbaum.

Van Dijk, T. A. (1992). La ciencia del texto. Barcelona: Ediciones Paidós Ibérica S.A.

Van Eemeren, F. H., Grootendorst, R., Henkemans, F. S., Blair, J. A., Johnson, R. H., Krabbe, E. C. W., Plantin, C., Walton, D. N., Willard, C. A., Woods, J. \& Zarefsky, D. (1996). Fundamentals of argumentation theory: A handbook of historical backgrounds and contemporary developments. Mahwah: Erlbaum.

Wertsch, J. V. (1991). Voices of the mind. Cambridge: Harvard University Press.

Recebido em 12.07.2006 Primeira decisão editorial em 27.10.2006 Versão final em 22.06.2007 Aceito em 06.08.2007 
III CONGRESO ARGENTINO DE SALUD MENTAL $3^{\circ}$ ENCUENTRO INTERAMERICANO DE SALUD MENTAL

Data: 27 a 29 de Março de 2008

Local: Buenos Aires, Argentina

Informações:

http://www.aasm.org.ar/ 